\title{
The Audience in Shame
}

\section{STEPHEN BERO}

\begin{abstract}
Many experiences of shame centrally involve exposure. This has suggested to a number of writers that shame is essentially a social emotion that involves being exposed to the view or appraisal of an audience-call this the Audience Thesis. Others reject the Audience Thesis on the basis of private experiences of shame that seem to involve no exposure. This disagreement marks a basic fault line in theorizing about shame.

I develop and explore a simple but effective way to shield the Audience Thesis from the private shame objection, by understanding the notion of an audience in a very minimal way. Rather than conceiving of the audience in terms of an other whose appraisal is an element in shame, we can conceive of shame generally as a response to appraisals of the subject-either by others or by the subject herself. On this view, shame requires an audience in the sense that it is not a first-order self-appraisal-like disappointment in or disapproval of oneself-but rather an appraisal of appraisals. This approach yields substantial benefits: it renders the private shame objection harmless; it explains why exposure cases strike us as particularly paradigmatic instances of shame; it clarifies what is happening when we feel shame before appraisals with which we do not agree; it helps to understand how it may be possible to feel shame in the face of neutral or even positive appraisals; and it captures a significant but neglected sense in which shame might be considered a social emotion.
\end{abstract}

Adam and Eve were naked without shame before they ate of the tree of knowledge; after eating they became ashamed and covered themselves with fig leaves. Other familiar experiences of shame also prominently involve exposure; think of the shame associated with intimate bodily functions, or the shame of being "caught in the act." Reflection on these and similar cases has produced a long tradition of understanding the gaze or, more generally, the appraisal of an audience to be an essential element in experiences of shame-call this the Audience Thesis. The Audience Thesis is one way to capture a widely held intuition that shame is, in some sense, a social emotion. 
But the Audience Thesis also has skeptics, who often argue that the thesis is contradicted by cases of private shame in which there is no audience. (There are other possible reasons for rejecting the Audience Thesis, but this frequently invoked argument will be my focus.) This results in a stalemate, in which advocates of the Audience Thesis seek to explain away purported cases of private shame, while critics of the thesis seek to explain away the intuition that shame is essentially social. This disagreement marks a basic fault line in theorizing about shame, and an obstacle to consensus and progress in our understanding of shame.

My general sympathies are with the Audience Thesis, and I propose here to explore a perhaps surprisingly simple way of rendering the private shame objection harmless, by reinterpreting the underlying notion of an audience. That notion is, naturally enough, widely understood in terms of an other - that is, an observer distinct from the subject of shame-whose gaze or appraisal is an essential element in shame experiences. The private shame objection is accordingly often met with efforts to locate this other somewhere within episodes of private shame-perhaps the other is merely imagined, or internalized, or abstracted, or consists in the subject of shame taking up an evaluative perspective that is somehow "detached" or distinct from her own.

But what if this ingenuity in the service of locating the elusive other is misplaced? If we simply put aside the idea that shame requires an "other," we could say instead that the role of the audience can be filled just as well by the subject of shame herself. Consistent with this, shame could still be a social emotion in the following sense: Rather than being a direct response to features of the subject (her appearance for example, or her competence or character), shame could be a response to perceptions or appraisals of those features. On this view, shame requires an audience in the sense that it is not a first-order self-appraisal-like disappointment in or disapproval of oneself-but is rather essentially an appraisal of appraisals. And this would mean that while shame may sometimes be a response to the perception or appraisal of an other (as in paradigmatic exposure cases like that of Adam and Eve), it need not be a response to such an appraisal-rather it may, at least in certain cases, be a response to one's own perception or appraisal of oneself. 
Two caveats are here in order: First, this is not intended as a general theory of shame, but rather as a hypothesis specifically about the role of an audience in the structure of shame. It thus remains neutral on a number of other important questions that a complete account of shame would need to address. Second, this proposal is not entirely without precedent; versions or aspects of it appear in several previous treatments of shame. ${ }^{1}$ But previous proposals along these lines have been encumbered with additional, and in my view unnecessary, claims or commitments; and moreover the possibility of interpreting the notion of the audience in this quite minimal way has not been widely appreciated or properly considered. ${ }^{2} \mathrm{My}$ aim is thus to strip away everything extraneous in order to isolate the central idea and to develop it as an answer to the private shame objection. I hope this will clarify the nature of the proposal and give it the visibility in theoretical discussions of shame that, in my view, it deserves.

For this simple approach yields substantial rewards: It handles cases of private shame without relying on controversial theoretical constructs (like imagined others or "detached" perspectives). At the same time, it provides an explanation of why it is that cases of exposure shame-which do essentially involve the gaze of an other-strike us as particularly paradigmatic, central cases of shame. Moreover, this approach makes sense of some of the rhetoric and imagery that are associated with shame; it clarifies what is happening when we feel shame in the face of negative appraisals with which we do not agree; and it provides a way to understand how it may be possible to feel shame in the face of appraisals that are neutral or even positive in character. Finally, it captures a significant and previously neglected sense in which shame-together perhaps with a range of other responses, like hurt feelings or gratitude ${ }^{3}$ - might be considered a social emotion.

${ }^{1}$ I have in mind particularly Gabriele Taylor's (1985) and Sarah Buss's (1999) accounts of shame, discussed below in $\int 4$.

${ }^{2}$ For instance, in a recent and significant book-length treatment of shame, a critical discussion of the claim that shame requires an audience considers three different ways of understanding this claim, none of which correspond to the understanding proposed here (see Deonna et al. 2012: 27-33; cf. Deonna \& Teroni 2011: 195-196).

${ }^{3}$ In this way, shame can serve as a case study for a possible broader inquiry into a class of "social" emotions defined in this way. 
In order to achieve these results, it will also be necessary to accept the additional claim that we can be emotionally invested in our own appraisals of ourselves in a way that is similar to the way in which we are emotionally invested in others' appraisals of us. While I will not argue in detail for this claim, I will indicate why I think it is independently plausible.

\section{The problem of the audience in shame}

I have said that the Audience Thesis is a common way of trying to capture the sense that shame is a social emotion. John Deigh, for instance, contends that "a satisfactory characterization must include in a central role one's concern for the opinion of others," and goes on to suggest that this is "really a lesson in recall. From Aristotle onward, discussions of shame have focused attention on the subject's concern for the opinions others have of him" (1996: 240). ${ }^{4}$ Similarly, Bernard Williams asserts that "shame and its motivations always involve in some way or other an idea of the gaze of another" (1993: 82); and Cheshire Calhoun contends that shame "seems intrinsically tied to the thought of social others' actual or imagined contempt" (2004: 131). These are all versions of the Audience Thesis; note that they all conceive the audience in terms of some other. ${ }^{5}$

But the Audience Thesis has also been said to be subject to decisive counterexample. Consider, for instance, the case of Sam, who has been working productively on an article all afternoon and initially feels quite pleased with the result. After a coffee break, however, he rereads his draft and in a flash realizes that what he had thought to be a compelling argument turns out to be a circular muddle, "contrived and badly written, the assertive tone unwarranted, the boldness pure defensiveness"; as a result, "Sam feels so ashamed” (Deonna \& Teroni 2011: 202). In

\footnotetext{
${ }^{4}$ In addition to Aristotle, Deigh cites Aquinas, Descartes, Spinoza, Darwin, and Sartre as incorporating a concern for others' opinions into their definitions of shame (1996: 240). Allegiance to the Audience Thesis thus cuts across philosophical traditions. Sartre, for example, writes that shame "is in its primary structure shame before somebody. . . . shame is shame of oneself before the Other" (1943: 302-303).

${ }^{5}$ See also, e.g., Maibom 2010: 569 and Galligan 2014: 64. The Audience Thesis also has proponents in the psychological literature. See particularly Leary 2007: 45, and also, e.g., Baldwin \& Baccus 2004, Kemeny et al. 2004, and Elison 2005.
} 
this case there appears to be no audience, as Sam has not shared his draft with anyone. He is, in short, alone in his shame.

On the strength of examples of private shame like Sam's, a number of theorists have rejected the Audience Thesis outright. Anthony O'Hear, for instance, contends that "it is quite possible to think of people, such as writers or craftsmen, with high standards of their own, feeling shame just because they have let themselves down (not produced a masterpiece), without thinking of them imagining other craftsmen inspecting and condemning their work"; he concludes, "shame does not then require the background of a real or imaginary audience" (1976: 77). John Kekes similarly argues simply that "we often feel shame when no one is present to observe us. So audience cannot be necessary" (1988: 284). And recently Julien Deonna and Fabrice Teroni (the authors of the Sam example) have run the same argument, noting that cases in which "shame is felt as a result of a failure to uphold a privately held ideal" are "common at least for some of us," and concluding from this that a "concern for others' opinions . . . is not always the relevant determinant of shame" (2011: 200). ${ }^{6}$

Critics of the Audience Thesis often seek to understand shame as a matter of the subject's own perception of a discrepancy between the ideals to which she holds herself and her actual situation. Kekes, for instance, holds that "What is essential to shame" is that we view "what we are, have, or do" as "falling short of some standard" (1988: 284); R. Jay Wallace defines shame as the feeling one has about "the lack of an excellence that one values and aspires to possess" (1994: 240); and Deonna, Teroni, and Raffaele Rodogno define shame in terms of one's awareness of an "incapacity to exemplify [a] self-relevant value" (2012: 102). ${ }^{7}$ According to these accounts, shame consists in a direct self-assessment by reference to the subject's own ideals, and makes no essential reference to any audience. For convenience I will refer to these and similar accounts as "personal-ideals" accounts of shame. ${ }^{8}$

${ }^{6}$ See also Deonna et al. 2012: ch. 5. This position is again also represented in the psychological literature. See, e.g., Tracy \& Robins 2007: 11.

See also, e.g., Nussbaum 2004: 184 and Mason 2010: 418-419. The psychologists Tracy and Robins similarly characterize shame in terms of personal ideals (2007: 11).

${ }^{8}$ A related family of views consists of what might be called self-esteem accounts. John Rawls, for instance, defines shame as "the feeling that someone has when he experi- 
Whatever other advantages personal-ideals accounts may have, rejecting the Audience Thesis carries a cost. But the difficult does not lie, as might be thought, in accounting for experiences of shame in which the presence of an actual audience is central-like the case of Adam and Eve, or cases in which the subject of shame is responding to others' ridicule, condescension, contempt, or the like. ${ }^{9}$ Personal-ideals accounts have little difficulty in accommodating these cases on their own terms. We need only accept that the relevant personal ideals include not only ideals of personal conduct or excellence, but also social or relational ideals that concern how we stand in relation to others. Then we can posit that Adam and Eve (after eating of the tree) treat it as an important ideal that each not be seen naked by the other (this might be an instance of some more general ideal ${ }^{10}$; and thus, when each of them perceives that she is seen in the way that she desires not to be, this represents a discrepancy between her personal ideals and her actual situation and is experienced as shameand similarly for cases of shame before ridicule, contempt, and so on. ${ }^{11}$

The costs of rejecting the Audience Thesis are thus of a different nature. Advocates of the Audience Thesis have raised a specific worry, but there is also a more general and, I think, potentially more serious one. The specific worry is that without the Audience Thesis, personal-ideals accounts will need some other way to account for the difference between shame and direct negative self-appraisals like disappointment in oneself. ${ }^{12}$ Contrast Sam's case with a nearly identical one:

Amy's high opinion of herself is derived in part from her belief that she writes excellent poetry, but she never shares any of her work with anyone else .... Then Amy reads some critical essays on poetry, and she becomes convinced that her own work lacks the characteristics

ences an injury to his self-respect or suffers a blow to his self-esteem" (1971: 442); see also Galligan 2014. For reasons of space I focus here on personal-ideals accounts.

${ }^{9}$ For examples of this sort of case and discussion, see Calhoun 2004: 128, 135-138; Deigh 1996: 233-235, 238; Maibom 2010: 572-573; Galligan 2014: 66.

${ }^{10}$ For instance, an ideal of being able to control one's self-presentation. For an account of shame that gives this ideal a central role, see Velleman 2001.

${ }^{11}$ For an example of this strategy for accommodating exposure shame within a personal-ideals account, see Deonna \& Teroni 2011: 208 and Deonna, Rodogno \& Teroni 2012: 129-31.

${ }^{12}$ For discussion of this point, see Deigh 1996: 231-232 and Deonna \& Teroni 2011: 211. 
for which she had previously valued it-her poems are stylistically ordinary and not especially insightful (Galligan 2014: 62).

Other than the fact that Amy writes poetry while Sam writes prose, Amy's case is virtually indistinguishable from Sam's. But unlike the authors of Sam's case, the author of Amy's case presents it as a situation in which the subject might not experience shame: "it does not seem to follow from this description that Amy must experience shame; certainly disappointment with herself . . . but not necessarily shame" (Galligan 2014: 62).

The problem here is not that we cannot see how Sam could experience shame in his circumstances; perhaps he might. The problem is rather that it would be just as consistent with the facts that we have been given for Sam not to experience shame, but only disappointment in himself, disapproval of himself, frustration with himself, or the like. This means that the factor that is responsible for making Sam's experience (but not Amy's) one of shame has been left out of the description of Sam's case. Falling short of one's ideals, by itself, seems to leave out something crucial that is distinctive in shame.

Personal-ideals accounts face the converse difficulty in exposure cases. Just as they do not explain why someone might experience private shame rather than merely disappointment, they also do not explain why we would expect someone in a case of unwelcome exposure to feel not merely disappointment but shame. Personalideals accounts seem to suggest that disappointment would be just as natural a thing for Adam and Eve to feel as shame when they discover that they are naked-but this is wrong. To feel only disappointment in such circumstances would be a bit odd; shame is not just one possible response to unwelcome exposure of this kind, but the characteristic response. ${ }^{13}$

In addition to this, there is a more general underlying worry. In accounting for cases of exposure shame in the way that they do, personal-ideals accounts treat those cases as mere instances of a much more general phenomenon; as a result, such accounts lose hold of the intuition that cases of exposure shame are somehow para-

\footnotetext{
${ }^{13}$ For one attempt to respond to these problems from the perspective of a personalideals account, see Deonna at al. 2012: 114-118. Very roughly, Deonna et al. suggest that negative self-appraisals like disappointment are generally "less severe" than shame (2012: 115). This strikes me, at least, as doubtful.
} 
digmatic, central cases of shame. While it would be contentious to deny that someone like Sam can experience shame privately, it nonetheless seems clear that cases like Sam's are not the most vivid or exemplary illustrations of the nature of shame. This intuition appears to be quite central to our shared conception of shame. If we were trying to teach an English learner the meaning of "shame," for instance, it would be simply confusing to offer Sam's case as an example; a case of unwelcome exposure, in which an audience is prominent, would be much more likely to put the learner on the right track. Personal-ideals accounts render this seemingly significant fact mysterious.

So the problem of private shame can be avoided by simply rejecting the Audience Thesis, but this tends to create other problems. Altogether this may not be decisive against personal-ideals accounts, but it at least provides a sense of what motivates advocates of the Audience Thesis to resist the private shame objection. If it were somehow possible, it would be ideal to have an answer to the problem of private shame that did not require wholesale rejection of the Audience Thesis.

\section{In search of the audience}

Advocates of the Audience Thesis often resist the critics' interpretation of experiences like Sam's by insisting, despite appearances, that there is an audience before which Sam feels shame. This requires locating the missing audience within the psychic mechanisms that produce Sam's experience of "private" shame. This internal audience can be located shallowly or more deeply within the subject's mind.

On a shallower level, experiences of private shame can be explained in terms of an imagined audience. Williams, for instance, calls it a "silly mistake" to suppose that shame always requires an actual audience, and suggests that "for many of [shame's] operations the imagined gaze of an imagined other will do" (1993: 81-82). Here he invokes Sartre's example of a voyeur who is looking through a keyhole and suddenly realizes that he himself is being watched from behind; Williams contends that "an imagined watcher could be enough to trigger the reactions of shame" (1993: 82). Williams then further proposes that the imagined audience might not consist in any specific, identifiable person, but could rather be an "internalized other" who is "abstracted and generalized and idealized," representing simply someone, other than 
the subject, who "can provide the focus of real social expectations ... of how my actions and reactions will alter my relations to the world about me" (1993: 84). More recently and in the same vein, Phillip Galligan proposes that in shame we "sometimes adopt others' perspectives without marking the shift as it happens, and the social perspective need not even be that of any particular person or group"; for instance, a cheater's shame "might result from imagining what it would be like to be known as a cheater, full-stop," without imagining any particular audience (2014: 67). And Krista Thomason similarly suggests that we "often think about how we 'look' in a way that is generalized and abstract," and that shame involves considering how we might look to a "representative person" who embodies "a social point of view-the point of view [of] any other person with a basic understanding of social relations and expectations" (2018: 81). ${ }^{14}$

According to proposals of this kind, cases of "private" shame are to be understood as shame before an imagined audience of a more or less rarified nature, which supplies the perspective of an other that is required by the Audience Thesis. So we should suppose that Sam feels ashamed because he either explicitly imagines what his discerning colleague would think if she were to read his sloppy draft, or (perhaps without realizing it) evaluates his draft from the imagined perspective of some unspecified, generalized, or representative other.

On a deeper level, experiences of private shame might be explained in terms of an audience that is not merely imagined, but rather internalized and incorporated into the subject's psyche in some more complex way. This is the route taken by Richard Wollheim (1999), drawing on psychoanalytic theory. ${ }^{15}$ Wollheim proposes that in developmental terms shame arises when what was simply fear of losing the love of an external figure is transformed, via "introjection" of the external figure, into shame. Here the audience, rather than a figment of the imagination of a unified subject, is conceived as a distinct psychic agency within a divided subject, an internal critic that operates in some sense independently and beneath the level of the subject's conscious awareness. In this picture, the audience is buried so deeply that it

${ }^{14}$ Thomason considers that this is true of at least many instances of shame, but remains agnostic as to whether it is a necessary condition of shame (2018: 83).

${ }^{15}$ Influential psychoanalytic accounts of shame include Piers and Singer 1953 and Lewis 1971. 
falls out of the subjective experience of shame, to play a behind-the-scenes explanatory role. So we should suppose that Sam feels shame because he is, unconsciously, subject to criticism from an introjected figure.

In presenting these strategies I have drawn a contrast between shallower and deeper versions in order to suggest that, in attempting to explain cases of private shame in terms of an internalized audience, advocates of the Audience Thesis face a dilemma. On the one hand, against the proposal that private shame is to be understood in terms of an imagined or generalized or representative audience of one sort or another, critics of the Audience Thesis can simply hold firm and deny that this explanation fits the evidence. We have already seen a version of this response in O'Hear's description of craftsmen who feel shame about their shoddy product "without ... imagining other craftsmen inspecting and condemning their work" (1976: 77). Similarly, against the idea of an imagined perspective that represents social expectations, Kekes reasons: "It is no use to postulate an imagined audience .... For we often feel shame for things that outsiders would not regard as shameful, such as ... falling short of some higher than accepted standard we have set for ourselves" (1988: 284).

In further support of this line, Deonna and Teroni observe that imagination is ordinarily "subject to the will and open to introspection" (2011: 196); that is, that although imagination can function spontaneously and without our attending directly to it, it nevertheless seems ordinarily to be at least accessible to introspection and some degree of control. And this means that if cases of private shame like Sam's are to be understood in terms of an imagined audience of some sort, then when we put ourselves in Sam's shoes and imaginatively reconstruct his experience as one of shame, we must thereby imagine some audience that his shame is felt in the eyes of - an audience that we ought to be able to locate introspectively, even if we had not originally attended to its presence. But it is at least far from obvious that merely in understanding Sam's experience as one of shame we are imagining such an audience. It seems open to critics of the Audience Thesis like O'Hear and Kekes to deny this.

On the other hand, against the proposal that private shame is to be understood in terms of a more elaborately and unconsciously internalized audience of the sort described by Wollheim, critics of the Audience Thesis can object, first, that this 
sort of explanation involves theoretical commitments that they can plausibly reject. The difficulty is that the sort of internal critic that Wollheim appeals to needs to be both sufficiently internalized by the subject to be firmly incorporated into her own psyche (and thus to operate at a deeper level than a merely imaginary audience) and sufficiently independent of and distinct from the subject to serve as the kind of other whose perspective, according to the most common interpretation of the Audience Thesis, is required for shame. Critics of the Audience Thesis who are not sympathetic to psychoanalytic explanations may reasonably be skeptical about the possibility of a psychic agency that straddles the divide between internal and external in this way. ${ }^{16}$

Second, this sort of view begins to look quite difficult to distinguish, in terms of the available evidence, from alternative views that reject the Audience Thesis (like personal-ideals accounts). The evidence from intuition and introspection that we can glean by considering a case like Sam's does not clearly distinguish between the competing views, precisely because the mechanism by which the perspective of an audience is supposedly engaged is, by hypothesis, operating beneath the level of the subject's conscious awareness. And here the critics of the Audience Thesis might argue that the simpler view which does not appeal to unconscious processes or dubious psychic agencies should be preferred. ${ }^{17}$

Advocates of the Audience Thesis are faced, then, with two difficult options. Either they can locate the audience on a relatively shallow level that is accessible to the subject's introspection, in which case critics of the Audience Thesis can simply deny that this is borne out by the evidence. Or they can locate the audience on a deeper, unconscious level, in which case critics can respond both that the proposed explanation is inherently dubious and that there are alternative explanations, not involving an audience, that require significantly fewer theoretical commitments.

\footnotetext{
${ }^{16}$ Thanks to Alex Sarch for help in formulating this problem. For a different criticism of Wollheim's account of shame, see Deonna \& Teroni 2011: 199 and Deonna et al. 2012: 129.

${ }^{17}$ The dilemma I have just described (minus the concern about the internal/external status of Wollheim's internal critic) is also succinctly stated by Tracy and Robbins (2004: 173).
} 


\section{The audience in shame}

The private shame objection thus represents a significant challenge for the Audience Thesis - at least if the notion of an audience is understood in terms of the gaze or appraisal of an other. But let us try now to understand the notion of an audience in a more minimal and general way; doing so, I will suggest, renders the private shame objection harmless while still giving meaningful substance to the idea that shame is a social emotion.

The proposal is simply to put aside the idea that shame requires an "other," and to say instead that the role of the audience can be filled just as well by the subject of shame herself. This can be done by positing that shame is not a direct response to features of the subject (her appearance for example, or her competence or character), but is rather essentially a response to perceptions or appraisals of those features either by others or by the subject herself. On this view, shame requires an audience in the sense that it is not a first-order self-appraisal-like disappointment in or disapproval of oneself_-but is, rather, essentially an appraisal of appraisals.

To be clear, the proposal is not that shame is always or essentially a response to one's own self-appraisals, nor that shame is never a direct response to the gaze or appraisal of an other-the idea is rather that shame is essentially a response to perceptions or appraisals of the subject, where these can be either the perceptions or appraisals of an other (as in exposure cases like Adam and Eve's), or the subject's own perceptions or appraisals of herself (as in cases of private shame).

It is important to understand what this proposal means for the structure of shame. Consider the case of Samantha, who like Sam has written a draft that she initially feels quite proud of, but who then immediately shows the draft to a discerning colleague for feedback. She feels shame when the colleague judges the draft to be a shoddy piece of work and disapprovingly tells Samantha "You can do better." If we are to understand Samantha's shame as a reaction to her colleague's appraisal, we need to be careful to distinguish the content of the colleague's appraisal-Samantha can do better-from the appraisal itself that has that content — the colleague's judgment that Samantha can do better. If Samantha were to come to agree that she could do better, she might have various attitudes about this-like disappointment in herself. But on the assumption that shame is a reaction to appraisals (rather than to their contents), 
none of these attitudes would be shame; rather, shame is an attitude that Samantha can only have about the distinct fact that (as it would appear to her) my colleague thinks that I, Samantha, can do better. Of course, Samantha's emotional reaction to her colleague's appraisal and her reaction to that appraisal's content (assuming she comes to endorse the content) often will overlap and may be difficult to distinguish in introspection; nonetheless, they are distinct.

We can draw the same distinction in any case of shame. For instance, when Adam is ashamed of his nakedness before Eve, we can say that his shame is a reaction not to the content of Eve's perception-that Adam is naked, or if you prefer, simply Adam's nakedness — but rather a reaction to Eve's perception that I am naked (or Eve's perception of my nakedness). In every case, according to this proposal, the experience of shame consists in the subject's response to being thought of or perceived in some way-rather than to the way in which he is thought of or perceived. In a slogan, then: Shame is a reaction to attitudes, not (just) to their contents.

The key point for our purposes, of course, is that there is nothing about the structure just described that dictates that the appraisal or attitude that is the object of shame must be an attitude of some other person (though of course it may be such an attitude). This marks a significant departure from the most common understanding of the Audience Thesis, and it immediately renders the private shame objection toothless. For in Sam's case we can just as well draw a distinction between the content of his appraisal (that Sam's draft is a shambles) and the appraisal itself (Sam's judgment that his draft is a shambles). And once we have distinguished these two things, we can distinguish Sam's attitudes about the fact that (as he would see it) my draft is a shambles_disappointment in himself, say-from his attitudes about the fact that $I$, Sam, judge that my draft is a shambles. Private shame, according to this proposal, is a response of the latter kind.

This fits nicely with the rhetoric and imagery that are often associated with shame before oneself. We say things like "I couldn't live with myself if I did that," or "I'm so ashamed I can't look myself in the mirror." Imagine that Sam (being a bit of a dramatic personality) says 'I'm so ashamed of this draft I can't look myself in the mirror!" Why might he say this, rather than (or perhaps in addition to) "I'm so ashamed of this draft I can't look at it"? The answer suggested by the current ap- 
proach is that these two acts-looking at the draft, and looking in the mirrorcorrespond to two different emotional objects. When he looks at the draft, Sam cannot avoid the thought that my draft is a shambles. By contrast, when he looks in the mirror the thought that Sam cannot avoid is quite different; it is the thought that $I$, Sam, judge that my draft is a shambles. And it is this thought, which describes an attitude that someone (namely, Sam) has about Sam, that is a possible basis not just for disappointment or other direct negative self-appraisal, but for the second-order appraisal of shame.

Now, this account requires the further claim that I mentioned in the introduction, namely that we can be emotionally invested in our own appraisals of ourselves in a way that is similar to the way in which we are often emotionally invested in others' appraisals of us. And while I will not argue for this in detail here, it strikes me as independently plausible. Shame before others is grounded in the kinds of relations that we have with those others and the ways in which we are emotionally invested in those relations. We are not, after all, equally liable to feel shame before everyone: a student might feel ashamed to be caught goofing off by her teacher but not by her peers; she might be ashamed to be caught studying diligently by her peers but not by her teacher. And she may be liable to shame before one teacher, or one peer, but not another. What determines these differences is the expectations and other attitudes of the various parties and the different ways in which the subject is invested in those attitudes. A student is liable to shame before one teacher but not another because she is emotionally invested in a distinctive way in the former's attitudes towards her but not the latter's. Before the latter's disapproval she might feel only annoyance or anxiety, but the former's disapproval touches her in the special, penetrating way that triggers shame.

Just as we have relationships of many different kinds with other people, we have relationships of many different kinds with ourselves, relationships that in various respects resemble (and developmentally, perhaps are modeled upon) the relationships we have with others. We love or hate ourselves, admire or ridicule ourselves, respect or disrespect ourselves, enjoy or dislike our own company, and so on. And these relationships, I am suggesting, can involve a similar depth of emotional investment to our relationships with other people. So for example, just as we are 
emotionally invested in whether or not, and to what degree, certain others respect us, we are typically emotionally invested in a similar way in whether or not, and to what degree, we respect ourselves. Shame before others is a response to an unwelcome gaze and reflects a sense that relations with others are not, in some way or other, as the subject would wish them to be; and in just the same way, shame before oneself can be a response to an unwelcome self-assessment and reflects a sense that the subject's relations with herself are not as she would wish them to be.

That is the essence of the proposal; the following sections will explore some of its relative advantages. But first it bears emphasizing again that what is being offered is a hypothesis specifically about the role of an audience in the structure of shame, not a general theory of shame. Among the important questions left unaddressed are, first: If what distinguishes shame from first-order self-appraisals (like disappointment in oneself) is that shame is a reaction to attitudes towards the subject, then what is it that distinguishes shame from other reactions that a subject might have to attitudes towards her-reactions like hurt feelings or gratitude? And second: Which attitudes towards the subject are potential objects of shame? Must the objects of shame be negative attitudes, or more specifically attitudes of ridicule, contempt, disrespect, or something else? Or is shame intelligible as a response to any attitude at all, provided only that the attitude in question is appropriately about or concerning the subject of shame ${ }^{18}$ The current proposal is compatible with a wide variety of answers to these questions.

\section{$4 \quad$ Two like-minded views}

This approach to understanding the Audience Thesis is not without precedent; two previous treatments with which it shares an affinity are Gabriele Taylor's (1985) and Sarah Buss's (1999). ${ }^{19}$ They both accord an important role in experiences

\footnotetext{
${ }^{18}$ This raises yet a third question not addressed here, namely what it means for an appraisal or attitude to be about the subject, in the way that is relevant for shame. It seems clear, for instance, that the attitude need not make direct reference to me in order for it to be about me in the relevant way. I could feel shame when I learn that someone has contempt for those who share my ethnicity or religion, even when that person has no idea that I exist.

${ }_{19}$ Thanks to Cecilea Mun for urging me to reconsider the significance of Taylor's view.
} 
of shame to an audience, and they both allow for private shame to be explained in terms of the subject of shame serving directly as her own audience. In these respects they are helpful models and allies. But both accounts also involve additional commitments or ambitions, and in particular additional claims about the role of the audience in shame, that put more distance than I think is necessary between the subject of shame and the audience's perspective. In my view a more minimal approach yields a cleaner and more satisfying response to the private shame objection.

Consider first Taylor, who accepts O’Hear's suggestion that a craftsman could feel shame just because he has failed to meet some high standard of his own (1985: 58). And yet she observes that to say merely that the subject of shame occupies an observer's position with respect to herself does not seem to be enough to explain the intuitively strong connection between shame and exposure. This connection involves, in Taylor's view, a more complex structure of self- awareness:

There is, then, this point to metaphors of an audience and of being seen: they reflect the structural features of the agent's becoming aware of the discrepancy between her own assumption about her state or action and a possible detached observer-description of this state or action, and of her further being aware that she ought not to be in a position where she could be so seen, where such a description at least appears to fit (1985: 66).

Thus, for Taylor the subject of shame becomes aware that she is seen in some way (by herself or others), and she reacts negatively to being seen or thought of in that way. And so private shame involves more than simply a direct first-order selfappraisal -it consists rather in the subject's reaction to her own self-appraisal. In this basic structure, my proposal matches Taylor's account.

But as is already apparent in the passage quoted above, there are a number of further elements in Taylor's understanding of the audience's role. I will focus on two of these. The first is the way Taylor conceives of the "detached" observer perspective. Shame, she says, "requires a sophisticated type of self-consciousness . . which centrally relies on the concept of another, for the thought of being seen as one might be seen by another is the catalyst for the emotion" (1985: 67). This means that private shame does not require actually imagining another observer, but it does require the subject to deploy the concept of another in order to achieve a view of herself as she might be seen by someone else. 
It is not entirely clear to me why Taylor includes this further conditionwhy, that is, she does not find it to be a sufficiently "sophisticated type of selfconsciousness" for the subject to be aware that she sees or thinks of herself in a certain way, without also invoking the concept of another. It is also perhaps not clear how substantive a difference this ultimately makes. But regardless, for my purposes this is at best distracting, because it invites the interpretation that what makes shame a social emotion for Taylor is that it essentially requires the subject to employ the concept of another, rather than that it essentially involves a structure in which the subject responds to the way in which she is seen. Of these, it is much easier for critics of the Audience Thesis to deny, by appealing to thought experiments like Sam's case, that shame necessarily involves employing the concept of another. But as I have suggested, the structural claim provides an independently interesting and generally overlooked sense in which shame may be a social emotion. ${ }^{20}$

Another element in Taylor's account that I propose to do without is her claim that shame involves a revelation or dramatic shift in view. This is connected to her idea that the subject becomes "aware of the discrepancy between her own assumption about her state or action and a possible detached observer-description of this state or action"; she argues that this involves a shift between "what she thought or hoped or unthinkingly assumed she was, or was doing, and what she has now under the observer-description turned out to be. This comes as a revelation to her" (1985: 66). No doubt many shame episodes have this dramatic, revelatory character; but it also seems quite plausible that many do not. ${ }^{21}$ With both this point and the previous one Taylor seems to me to be making more than is necessary out of the dis-

${ }^{20}$ Indeed, Deonna et al., in the course of arguing that shame is not an essentially social emotion, consider Taylor's claim that shame relies on the concept of another, and offer arguments to refute this claim; but they simply ignore the structure of Taylor's account and the distinct sense in which this structure makes shame a social emotion (2012: 146-149).

${ }^{21}$ To take an extreme sort of example, a perversely motivated individual can pursue or continue a course of action knowing full well that it is a source shame, and indeed even do this precisely because it is so-for instance because she wishes to prove that she will not be cowed by shame. The behavior of the father, Fyodor Pavlovich Karamazov, in Dostoevsky's The Brothers Karamazov provides abundant, vivid examples of this sort of perversity. (For similar criticism of the idea that shame essentially involves a dramatic revelation, see Deonna et al. 2012: 149-150.) 
tance between the subject of shame and the "detached" observer perspective that is part of the structure of shame. This plays into the hands of those who would press the private shame objection against the Audience Thesis; but my more minimal understanding of the audience avoids this.

Consider now Sarah Buss's (1999) account of shame. Buss suggests both that "to experience shame is to experience oneself as an object of appraisal," and that this can be extended to cases of private shame by recognizing that "insofar as one is the source of one's ideals, one is critical of one's behavior; and insofar as one is the object evaluated in light of these ideals, one is ashamed of this behavior" (1999: 531). For Buss, then, private shame is a matter of responding to one's own self-directed attitudes; on this fundamental point Taylor, Buss, and my proposal are again all in agreement.

But Buss's view also includes elements that my proposal does without. I will discuss one here and defer another to the next section. The first is that Buss believes that the structure of private shame involves a "divided consciousness" in which the subject occupies two different "evaluative perspectives," corresponding to the position of "the critic" who appraises and the distinct position of the object of that appraisal (1999: 531-32). Buss's approach here is motivated in part by larger theoretical ambitions concerning the significance of shame. ${ }^{22}$ But taken solely on its own terms, Buss's resort to a "divided consciousness" appears unnecessarily to conflate two distinctions: the distinction between two different positions- the positions of subject and object of appraisal—and the distinction between two different "evaluative perspectives." These two distinctions can come apart; someone can occupy the positions of both subject and object of appraisal without occupying different evaluative perspectives. A vain person, for example, can both admire his own appearance (just as he would admire the appearance of a similarly dapper stranger) and take pleasure in the fact that he is so admired-admired, that is, by himself. Here the vain person simultaneously occupies the position of subject and object of appraisal, but without any divided consciousness. His two relevant attitudes-roughly: I'm so dapper

\footnotetext{
${ }^{22}$ Buss assigns shame a central role in her account of how it is that we ordinarily develop a sense of respect for other persons generally; shame is, according to her view, one of the chief ways in which we come to recognize that others' evaluative perspectives are independent sources of reasons for us (1999: 525-527).
} 
and It's wonderful that someone (namely me) thinks that I'm so dapper-reflect these two different positions, but they are mutually compatible and can issue from a unified evaluative perspective.

According to both Buss's view and my proposal, someone who feels private shame, like Sam, is similar to the vain person in both appraising himself in a certain way (thus occupying the position of subject of appraisal), and simultaneously responding to that appraisal (thus occupying the position of object). But as in the case of the vain person, Sam's relevant attitudes can reflect the two different positions that he occupies while being mutually compatible and issuing from within a single evaluative perspective. And so for my purposes at least, Buss's view, like Taylor's, seems to make more than is necessary out of the distance between the subject of shame and the observer perspective that is part of the structure of shame.

To review, then, my proposal follows in the footsteps of these predecessors insofar as both Taylor and Buss consider shame to be essentially a response to appraisals of the subject of shame, which enables them to explain cases of private shame in terms of the subject's response to her own self-appraisals. But there is also a crucial difference. I have tried to show how attributing this simple structure to shame can render the private shame objection harmless, by making it easy to understand a case like Sam's in terms of the subject's response to his own self-appraisal. But Taylor and Buss both, in different ways, compromise this simplicity by building further features into the shame experience (like the concept of another, or a "divided consciousness") that obscure the underlying structure by distancing the subject of private shame from the audience perspective. In this way, they both provide an unnecessarily easy target for the private shame objection, because critics of the Audience Thesis can point to Sam's case and argue that there need be no such distance for Sam to feel shame. ${ }^{23}$ Again, my more minimal understanding of the audience avoids this, by attributing to shame a simple structure that provides a clean and satisfying response to the private shame objection.

\section{$5 \quad$ Taking stock}

${ }^{23}$ And to reiterate, some critics of the Audience Thesis have effectively done exactly this—see footnote 20 above. 
While it is consistent with my account that there are subjects (like Williams's version of Sartre's voyeur) whose shame is grounded in the gaze of an imagined audience, it is also unnecessary to posit any such other-even in the thin sense of a "detached" or distinct evaluative perspective-to explain a case like Sam's. Rather, the explanation of Sam's shame can lie in the fact that Sam serves as his own audience, simply in virtue of his capacity to have self-directed attitudes and to be emotionally invested in the right way in what those attitudes are. The key to understanding Sam's shame, I have suggested, is that it is not just a self-directed attitude (like disappointment in himself, or disapproval of himself), but rather a self-directed attitude of a very particular kind; namely, an attitude about a self-directed attitude. And it is important to be clear that it is an attitude about that self-directed attitude itself, rather than about the content of that attitude.

It is not difficult to understand why the theoretical significance of the distinction between the contents of one's own self-directed attitudes and the attitudes themselves might be overlooked. In cases of shame before others, it is at least plausible that the subject of shame need not endorse the assessment that forms the basis for her shame-this is why a subject can feel shame in the face of attitudes towards her with which she in no way agrees, such as contempt for her ethnicity or religion. Such a subject is clearly reacting to the attitude of the audience, rather than directly to the content of that attitude (in the absence of the hostile attitude itself, merely considering the content would be no occasion for shame). But this distinction is more difficult to appreciate in cases of private shame, because Sam's shame, for example, is based on the thought that I, Sam, judge that my draft is a shambles, and in order to have this thought Sam ordinarily must also have the thought that my draft is a shambles. So when speaking of private shame we cannot point to any familiar sort of case in which the "audience" and the subject disagree to illustrate that it is the attitude, rather than its content, that is the focus of shame. But once this is pointed out it can readily be seen that the subject's attitudes about some content, and her attitudes about an attitude that has that content, are quite distinct.

Careful attention to this distinction can also help to resolve another potentially perplexing issue that is illustrated by, though hardly unique to, Buss's view of shame. Buss holds that feeling shame in response to some appraisal—whether one's 
own or that of another-must involve in one way or another agreeing with or crediting the content of that appraisal. ${ }^{24}$ She says, for instance, that to feel "shame is to discover that one's actions have a meaning which one must affirm even though it is not conditional upon one's own point of view" (1999: 526), that "shame is an acknowledgment that one is, indeed, this very object-that one is as seen" (1999: 527), and that "shame is, intrinsically and essentially, the experience of an external authoritythe experience of the authority of an external point of view" (1999: 533).

These characterizations may fit some shame experiences, but are at least doubtful when applied to the cases just mentioned in which the subject appears to disagree, on the level of explicit judgment, with the attitude that is the focus of shame. And they founder completely when applied to a case of unwelcome exposure like that of Adam and Eve. The reason for this is that Eve's attitude, after eating of the tree, towards Adam's nakedness (like Adam's attitude towards Eve's) need not be critical — it might indeed be admiring-but Adam could still very well respond to Eve's perception of his nakedness with shame. If we are to suppose that Adam's experience of shame involves an experience of Eve's “external authority," or an experience that he "is as seen" by Eve, then in this scenario his shame would involve in some way experiencing his naked body as, or accepting on Eve's authority that his nakedness is, pleasing to the eye. But it is not obvious how an experience of this sort could be a basis for shame.

A widely discussed example that vividly illustrates this problem concerns an artist and his nude model. ${ }^{25}$ The model understands her relationship with the artist to be purely professional and is comfortable with her role, until one day in the middle of a sitting she realizes that the artist no longer sees her solely as a subject to be painted, but has come to see her in a sexual light. With this realization, the model suddenly and for the first time has the sense that she is compromised in her nudity, and feels a rush of shame. As with Adam and Eve, the model's shame consists in

${ }^{24}$ This is the other way, anticipated in the previous section, in which Buss makes more out of the notion of the audience than is necessary for my purposes. By contrast, Taylor's treatment of this issue and mine are similar (1985: 60, 64-65).

${ }^{25}$ This case, originally concocted by Max Scheler, was, as far as I know, introduced into the English-language literature by Taylor (1985: 60-61), and is also discussed by Williams (1993: 220-221) and Wollheim (1999: 159-160). 
feeling exposed to an unwelcome gaze. But this example illustrates more clearly than the example of Adam and Eve that the basis for shame is not simply nudity, or the subject's discomfort with her own naked body, but rather more specifically the audience's attitude - after all, the only difference between the original situation, in which the model is at ease, and the later situation is the artist's attitude towards her. And here again, we can easily imagine that the model understands the artist's attitude to be entirely approving. ${ }^{26}$ If the model's experience of shame is supposed to involve an experience of the artist's "external authority," or an experience that she "is as seen" by the artist, then the model's shame will involve in some way seeing herself as, or accepting on the artist's authority that she is, sexually attractive. But, again, it is not obvious how an experience of this sort could account for the model's feeling of shame.

The model's experience nicely illustrates how shame is a possible response even to approving attitudes. Nakedness and sexual behavior provide vivid examples of this, but the same phenomenon can also be found in a variety of cases in which the zone of privacy that we consider important to maintain is intruded upon, exposing even entirely admirable activities (artistic, sentimental, intimate, etc.) to unwelcome publicity. To borrow an observation from Thomas Nagel: "The boundary between what we reveal and what we do not, and some control over that boundary, are among the most important attributes of our humanity"; for this reason, it is often the case that we "don't want to expose ourselves completely to strangers" — or even, we might add, to friends and intimates_- "even if we don't fear their disapproval, hostility, or disgust" (1998: 4).

Another class of cases in which shame may be felt in the face of approving attitudes involves what we might call the wrong kind of approval. As Williams remarks, "the view taken by the observer need not itself be critical: people can be ashamed of being admired by the wrong audience in the wrong way" (1993: 82). This can occur, for instance, for subjects who have experienced significant changes of heart. Consider someone who had once been an open and prominent white supremacist or homophobe, but then came to see the error of her ways and to feel deep remorse for her past conduct. When she hears admirers who share her former

${ }^{26}$ As Taylor also observes (1985: 61). 
hateful views (and who may not realize that she has had a change of mind) praising her contributions to the cause, she might well be ashamed before their admiration. ${ }^{27}$

All of these cases, in which the attitude that is the basis for shame is not negative or critical of the subject, illustrate the error when thinking about shame of conflating two different emotional objects: the content of an attitude, and the attitude itself. The model's shame, for instance, cannot be made sense of as a reaction to the content of the artist's attitude- to the thought that (as the model would see it) $I$ am sexually attractive; after all the same thought, had in connection with her lover or simply as a direct self-assessment, would tend to arouse no shame at all. It is the fact that she is sexually attractive to this observer on this occasion that is experienced as unwelcome and that engenders her shame. To make sense of her shame we must then understand it as a reaction to the perception that I am seen by the artist as sexually attractive; it is this that she is reacting negatively to when she experiences shame. Contrary to Buss's characterization, it would seem to have nothing to do with the "authority" of the artist with respect to her sexual attractiveness, or with whether the model somehow affirms or acknowledges the content of his attitude; it has to do, rather, with her discomfort at being seen in this way on this occasion. To be so seen does not sit well with her. And something similar could be said about other cases in which shame is felt in the face of approving attitudes.

Of course, when we feel shame the attitudes that we are reacting to often are negative or critical in content, and sometimes we agree with the contents of those attitudes. This agreement can form the basis for other negative attitudesdisappointment in ourselves, disapproval of ourselves, anger with ourselves - that are painful and unpleasant, and this cocktail of concomitant emotions very often exacerbates the unpleasantness of shame experiences. But if the foregoing analysis is correct, then it is important not to conflate these common concomitants with shame itself; they are not the essence of shame.

\footnotetext{
${ }^{27}$ Note that this class of cases involves a confounding factor that is absent from the unwelcome exposure cases (including the model case), namely that in these cases the subject of shame sees the circumstance that is the ground for others' admiration as a reason for negative self-evaluation (independently of others' admiration). This means that the former bigot might also feel shame before her own disapproval.
} 
I have argued that an almost deceptively simple way to shield the Audience Thesis from the private shame objection is to adopt a quite minimal understanding of the notion of an audience. Rather than conceiving the audience in terms of an other-that is, an observer distinct from the subject of shame-whose gaze or appraisal is an essential element in shame experiences, we can conceive of the audience much more generally in terms of perceptions or appraisals of the subject, where these can be the perceptions or appraisals either of another (perhaps imagined) person or of the subject herself. Shame can then be said to require an audience in the sense that it is essentially a response to such appraisals, rather than a direct response by the subject to some feature of herself; the proposal is, in other words, that shame is not a first-order self-appraisal—-like disappointment in or disapproval of oneselfbut is, rather, essentially an appraisal of appraisals.

This proposal renders the private shame objection harmless because it provides a meaningful sense in which an audience is present even in cases of private shame (by capturing how we can serve directly as our own audience), but does so in the most minimal possible way, without positing additional elements-like an imagined, internalized, or abstracted other; or a "detached" or distinct evaluative perspective - that proponents of the private shame objection could reject as otiose.

Moreover, this proposal allows a distinction to be drawn between the contents of the attitudes that shame is a reaction to, and the attitudes themselves. Keeping this distinction in mind enables us to explain why exposure cases strike us as particularly paradigmatic instances of shame. It is because in exposure cases the shame and the attitude that is the object of shame are separated across different subjects, thus vividly exhibiting the distinctive social structure of shame.

Acknowledgments: Special thanks to Andrei Marmor, Jon Quong, Alex Sarch, Mark Schroeder, Beth Snyder, Gary Watson, Aness Webster, and an anonymous reviewer for this journal, as well as to an audience at the 2017 Pacific APA and to Cecilea Mun for helpful comments on that occasion. This work has been supported in part by a University of Southern California Provost's PhD Fellowship and by an Irving and Jeanne Glovin Award given by the Oskar Schindler Humanities Foundation. 


\section{References}

Baldwin, M.W., \& Baccus, J.R. (2004). Maintaining a Focus on the Social Goals Underlying Self-Conscious Emotions. Psychological Inquiry 15(2), 139-144.

Buss, S. (1999). Respect for Persons. Canadian Journal of Philosophy 29(4), 517-550.

Calhoun, C. (2004). An Apology for Moral Shame. Journal of Political Philosophy 12(2), 127-146.

Deigh, J. (1996). Shame and Self-Esteem: A Critique. In The Sources of Moral Agency (pp. 226-247). Cambridge: Cambridge University Press.

Deonna, J., \& Teroni, F. (2011). Is Shame a Social Emotion? In A. Konzelmann Ziv, K. Lehrer \& H.B. Schmid (Eds.), Self-Evaluation: Affective and Social Grounds of Intentionality, Philosophical Studies Series 116, 193-212.

Deonna, J.A., Rodogno, R., \& Teroni, F. (2012). In Defense of Shame: The Faces of an Emotion. Oxford: Oxford University Press.

Elison, J. (2005). Shame and Guilt: A Hundred Years of Apples and Oranges. New Ideas in Psychology 23, 5-32.

Galligan, P. (2014). Shame, Publicity, and Self-Esteem. Ratio (New Series) March 2016, 29(1), 57-72.

Kekes, J. (1988). Shame and Moral Progress. Midwest Studies in Philosophy 13, 282-296.

Kemeny, M E., Gruenewald, T.L., \& Dickerson, S.S. (2004). Shame as the Emotional Response to Threat to the Social Self: Implications for Behavior, Physiology, and Health. Psychological Inquiry 15(2), 153-160.

Leary, M.R. (2007). How the Self Became Involved in Affective Experience; Three Sources of Self-Reflective Emotions. In J. Tracy, R.W. Robins, \& J.P. Tangney, (Eds.), The Self-Conscious Emotions: Theory and Research (pp. 38-52). New York: The Guilford Press.

Lewis, H.B. (1971). Shame and Guilt in Neurosis. Psychoanalytic Review 58(3), 419-438.

Maibom, H.L. (2010). The Descent of Shame. Philosophy and Phenomenological Research 80(3), 566-594.

Mason, M. (2010). On Shamelessness. Philosophical Papers 39(3), 401-425.

Nagel, T. (1998). Concealment and Exposure. Philosophy \& Public Affairs 27(1), 3-30.

Nussbaum, M. (2004). Hiding from Humanity: Disgust, Shame, and the Law. Princeton, NJ: Princeton University Press.

O'Hear, A. (1976). Guilt and Shame as Moral Concepts. Proceedings of the Aristotelian Society (New Series) 77, 73-86.

Piers, G. \& Singer, M.B. (1953). Shame and Guilt: A Psychoanalytic and a Cultural Study. Springfield, IL: Charles C. Thomas.

Rawls, J. (1971). A Theory of Justice. Cambridge, MA: Harvard University Press.

Sartre, J.-P. (1943). Being and Nothingness: A Phenomenological Essay on Ontology (Hazel E. 
Barnes, Trans.). New York: Washington Square Press.

Taylor, G. (1985). Pride, Shame, and Guilt: Emotions of Self-Assessment. Oxford: Clarendon Press.

Thomason, K. (2018). Naked: The Dark Side of Shame and Moral Life. Oxford: Oxford University Press.

Tracy, J.L., \& Robins, R.W. (2004). Keeping the Self in Self-Conscious Emotions: Further Arguments for a Theoretical Model. Psychological Inquiry 15(2), 171-177.

Tracy, J.L., \& Robins, R.W. (2007). The Self in Self-Conscious Emotions: A Cognitive Appraisal Approach. In J. Tracy, R.W. Robins, \& J.P. Tangney, (Eds.), The Self-Conscious Emotions: Theory and Research (pp. 3-20). New York: The Guilford Press.

Velleman, J.D. (2001). The Genesis of Shame. Philosopby \& Public Affairs 30(1), 27-52.

Wallace, R.J. (1994). Responsibility and the Moral Sentiments. Cambridge, MA: Harvard University Press.

Williams, B. (1993). Shame and Necessity. Berkeley, CA: University of California Press.

Wollheim, R. (1999). On the Emotions. New Haven, CT: Yale University Press. 